\title{
The Energy Saving Device for Allocation Fibrous and Roughly of Impurities from Technological Drains of Coloured-Finishing Manufacture
}

\author{
S. M. Khurramova ${ }^{1}$ \\ ${ }^{1}$ Karshi State University Republic of Uzbekistan, Republic of Uzbekistan \\ Correspondence: S. M. Khurramova, Karshi State University Republic of Uzbekistan, Republic of Uzbekistan. \\ E-mail: khurramova_2018@mail.ru
}

Received: June 10, 2019

Accepted: June 26, 2019

Online Published: June 30, 2019

doi:10.5539/mer.v9n1p8

URL: https://doi.org/10.5539/mer.v9n1p8

\begin{abstract}
In clause are submitted developed by the authors a design energy saving the device for allocation fibrous and roughly of impurities from technological drains of colored-finishing manufacture. The device can be used on any distances of shop, the design simple, conveniently fast installation and dismantle, prevents a contamination of sewer networks, promotes more stable work subsequent of clearing and simplifies their operation.
\end{abstract}

Keywords: the filtering device, technological drain, fibrous and of impurity, colored-finishing

\section{Introduction}

Preparing cotton fabrics for dyeing is the most environmentally harmful process, since it accounts for $50 \%$ of all production effluents. When preparing materials from cotton for dyeing the first stage of its processing in the working bath of the equipment, up to $6 \%$ of fibrous and coarse dispersed impurities from the mass of the treated fabrics are formed. Because of this, during the operation of the sewer network, problems such as blockages, silting, germination and development of roots in networks and breakdown of pumping units in sewage pumping stations arise. The normal conditions of transportation of waste liquid are violated.

At present, with a large variety of high-tech solutions for the treatment of industrial wastewaters, there are no production options that allow to clean specific pollutants at low cost. An analysis of recent research and publications of scientific and technical information shows that the structures used are, as a rule, "universal" and do not take fully into account the characteristics of the cleaned technological production effluent. The search for highly efficient, technological and cost-effective solutions for the organization of specific treatment of discharged technological production effluents is very necessary, which facilitates and reduces the price of further deeper cleaning methods (Efimov, Tavartkiladze, \& Tkachenko, 1985; Laskov, 1988).

The main goal of our work is to show the practical possibilities of the complete isolation of fibrous and coarse dispersed impurities from the discharged technological waste from the decorating of the dyeing and finishing production with an affordable energy-saving filtering device.

\section{Experimental Methods}

We used standard methods for the chemical analysis of wastewater and the measurement of the physicomechanical characteristics of the filter material. The measurements were carried out in accordance with the regulatory and technical documentation.

\section{Results and Discussion}

For production testing the device as a base object was selected discharged technological drain decoction from the working bath of high-speed jigger MGSBG-Italia of periodic action, in the city of Karshi "Cotton road".

The device is installed before lowering the sewer patch and hermetically fastened with a clamp 5, on the free end of the drain pipe 8 , equipment.

Discharged molded part of the process flow from the equipment bath, the internal cavity of the cylindrical body 1 is guided through the drain pipe, and is passed through the filter element 2. The filter element is U-shaped cylindrical in shape during assembly and the device is installed with open and closed sides in opposite directions. , between the 
metal mesh layer 3. The filtering element is reinforced with the help of a wire mesh on the metal mesh cells with the possibility of replacement. Layers of metal mesh in parallel secured inside the cylindrical body with the possibility of dismantling. Purified drainage from fibrous and coarse impurities is discharged using a cylindrical gap 4, and drained into a sewer tray 9. To replace or clean the filter element, a removable cover 6 is opened, using folding bolts 7, providing connections.

Experimental data show that the capture and accumulation of fibrous impurities occurs on the surface of the filter material. After atmospheric drying, the trapped fibrous impurities are removed from the surface of the filter element using metal hooks, precipitating contamination by shaking. The figure shows the scheme of the device.

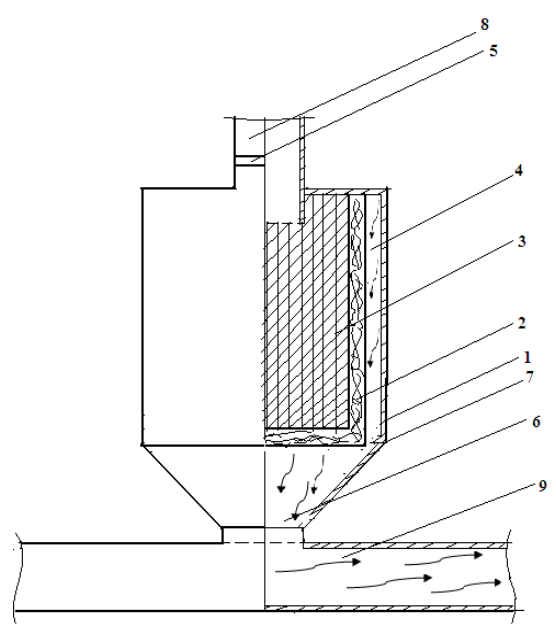

Figure 1. Device layout

1-cylindrical body, 2-filter material, 3-metal mesh, 4-cylindrical gap, 5-collar, 6-removable cover, 7-folding bolts, 8 -drain equipment pipe, 9-sewer tray.

Technical characteristics of the device are given in the table below.

\begin{tabular}{llll}
\hline № & Parameters name & Unit of measurement & Amount \\
\hline 1 & Weight & $\mathrm{kg}$ & 6,0 \\
2 & Height & $\mathrm{mm}$ & 800 \\
3 & Diametr & $\mathrm{mm}$ & 400 \\
4 & Number of cells in metal mesh & pieces & 7626 \\
5 & Size of single cells in metal mesh & $\mathrm{mm}^{2}$ & 30 \\
6 & Clearance width for draining purified water & $\mathrm{mm}^{2}$ & 140 \\
7 & The volume of the filter element in the device & $\mathrm{m}^{2}$ & 0,8 \\
8 & The mass of a single-layer filter material in the device & $\mathrm{gr}$ & 276 \\
\hline
\end{tabular}

The device except the filter material is completely made of stainless steel, which guarantees a long service life and has less material consumption. It is possible to manufacture according to individual specifications (MGHurramov, Khurramova, Khurramova, \& Shainazarov, 2018).

The main working body of the device is the filter material. As a source of raw materials for the production of filtering material, ripe cylindrical, biopolymer, solid, netted fruits, renewable luffa plant, with an average weight of $40-45 \mathrm{gr}$, length $440-450 \mathrm{~mm}$ and diameter $220-250 \mathrm{~mm}$ were used. From an environmental point of view, experience has shown that cultivation of loofah does not require pesticides and herbicides, does not accumulate toxic substances in itself, and there is no negative impact from direct and indirect contact on human health. From an economic point of view, the available raw materials. The sequence of obtaining the filtering material includes the following stages: at the initial stage, the peel of the fruit is peeled off with a metal brush, and the ribs of the peel are separated to produce sewing monofilament. Then, peeled biopolymer fruits are cut into rectangular pieces, from which, with cutting, the internal vascular bundles and seeds are separated. The volumetric-spatial formation of rectangular pieces 
with ironing and pulling is carried out. Separate rectangular pieces with monofilaments obtained from the ribs of the peel with a linear density of 280tex, are stitched together to form a single system of a given length and width. The resulting filter material has a surface density of $345 \mathrm{~g} / \mathrm{m} 2$, with a thickness of $3 \mathrm{~mm}$.

\section{Findings}

The results of an experimental study showed that the amount of retained fibrous and coarse impurities after decoction of 1000 meters of cotton fabrics in the filter is $8.6 \mathrm{~kg} /$ day; humidity $70-80 \%$; ash content $5-7 \%$. The device can be used at any workshop distance, vertical or horizontal position with the help of the following spare parts: nozzles, elbows, hoses and pipes. The design of the device is simple, convenient for quick installation and disassembly and is easily replaced by a filter element. The use of the device prevents clogging of sewage networks, contributes to more stable operation of subsequent treatment facilities and simplifies their operation.

\section{References}

Efimov, A. Y., Tavartkiladze, I. M., \& Tkachenko, L. I. (1985). Wastewater treatment of light industry enterprises. Kiev: Technique.

Laskov, Y. M. (1988). Sectoral collection of methods for the chemical analysis of substances used in light industry contained in wastewater [Text]: guidance document. TSNIITEI.

MGHurramov, D. M., Khurramova, S., Khurramova, M., \& Shainazarov, R. M. (2018). Patent for a utility model of the Republic of Uzbekistan No. FAP 01314. UZ. A device for cleaning waste fiber and coarse impurities (Publ. 06.07.2018).

\section{Copyrights}

Copyright for this article is retained by the author(s), with first publication rights granted to the journal.

This is an open-access article distributed under the terms and conditions of the Creative Commons Attribution license (http://creativecommons.org/licenses/by/4.0/). 